\section{UNCOMMON ACCIDENTS FOLLOWING OPERATIONS IN THE NOSE AND THROAT.}

Read in the Section on Laryngology and Otology, at the Forty-seventh Anvial Meeting of the Ameriean Medical Association, at Atlanta, Ga.. May 5-8, 1896.

BY MAX THORNER, A.M., M.D.

PROFESSOR OF CLINIC LARYNGOLOGY AND OTOLOGY, CINCINNATI COLLEGE OF MEDICINE AND SURGERY; LARYNGOLOGIST AND AURIST, CINCINNATI HOSPITAL, ETC. CINCINNATI, OHIO.

It is now almost ten years that the late Professor Nussbaum commenced his monograph "On Accidents in Surgery" with these words: "Of surgical accidents, avoidable ones as well as unavoidable, there are so many, that if one would attempt to enumerate them all one would hardly know where to begin and where to end. Unfortunately, owing to human vanity, almost exclusively successful cases are reported, while unfortunate events are not published, although one unfortunate accident is often more instructive than ten successful cases." Such considerations have prompted me to report to you to-day a number of accidents following operations in the nose and throat, which have happened during the last eleven years. do not attempt to enumerate all or even the majority of undesirable sequelæ that I have seen; but I purposely omit all such cases, as are frequently observed and have often been described, for instance lacunar tonsillitis or pharyngitis following intra-nasal operations; acute purulent otitis with or without complications, adhesions forming in the nose, epistaxis, etc. But I shall confine my remarks to a few cases which are rather remarkable on account of their rarity.

Case 1. Functional aphonia, following cauterization of the pharynx for chronic follicular pharyngitis. The patient was a young lady, 18 years old, who was studying elocution. She was referred to me on account of her voice failing during any prolonged attempt at loud reading or speaking. She had a well developed chronic lateral and follicular pharyngitis, and some remnants of adenoid vegetations, in cushion shape, at the vault of the pharynx.

Treatment consisted mainly in galvano-cauterizations, repeated at intervals of from eight to twelve days. One day after a number of treatments had been given with a very noticeable improvement of the voice, a large hypertrophied fol licle, situated nearly in the center of the posterior pharyngeal wall was cauterized, when suddenly the patient said in a whisper that her voice was gone. There was complete aphonia. I was naturally alarmed. Upon laryngoscopic examination the image was found to be the same as in functional aphonia; the vocal cords approximated during an attempt at phonation for an instant, but separated again at once. This condition lasted for a few days, when it vanished almost as suddenly as it had appeared, without any special treatment. There was at no time a recurrence of this reflex phenomenon, although the same treatment was continued for some time, with the result of entirely restoring the voice of my patient. This patient was a strong and healthy young woman, and did not at that or any time thereafter belong to the great army of hysteric women.

Case 2. Temporary amaurosis following cauterization of the nose. Mr. J. H., 40 years old, was under my care about ten years ago for nasal polypi. A great many of them were removed by the cold wire snare. When the nose was thor oughly cleared there remained a few very small ones in the crevice between lower and middle turbinated bodies, which could not be engaged in the snare. I decided to destroy them with the galvano-caustic burner. One day, following such a treatment on the previous afternoon, $\mathrm{Mr}$. H. called on me in great excitement, telling me that he could not see with the right eye, the side operated upon. The eye, upon examination did not show any difference from the normal; he could discriminate between light and dark, could see objects held closely before his right eye, but could not count fingers at a distance of five feet. Ophthalmoscopic examination was entirely nega tive. Vision improved after five days and was gradually and entirely restored within four or five weeks.

Case 3. Loss of memory following an insignificant opera tion in the nose. A boy of about 16 years of age, from one of the interior towns of Ohio, was operated upon for almost complete nasal obstruction. There was a marked deviation of the septum and enormous hypertrophies of the lower and middle turbinated bodies. These hypertrophies were removed at intervals of from four to six weeks, the boy returning to his home after each operation. After two or three operations had been done, without any untoward symptoms, the boy returned for another operation. This time I succeeded in removing but a small piece, the size of a green pea, from the middle turbinated. There was but moderate hemorrhage, but as the boy had just passed through an attack of tonsillitis, I decided not to do any more. I saw him the following day at $10 \mathrm{~A}$. M., found him apparently in good condition, and he left on an afternoon train. When he arrived home about four hours later, he was in an almost absent-minded condition. During the night the family physician telegraphed me to inquire what anesthetic had been used. I learned the following day from a letter of the physician that the boy had a high temperature when he arrived, his conjunctiva were hyperamic, pupils dilated, he was complaining of headache, and above all was absolutely unconscious of everything that had happened since he left home. The pain and fever subsided within two days; the pupils became again normal; but the loss of memory remained for about six weeks, during which time his mental activity was very much impaired. Gradually during the course of the next two or three months, all his mental faculties returned, although the memory remained sluggish for some time. When I saw him several months thereafter, he was in perfect health and his parents had the courage to have the treatment continued, which was thoroughly successful without any further accident.

Case 4. Intubation in an adult followed by a fatal edema of the larynx after extraction of the tube. J. B., 18 years old, had been suffering eight years from what was considered asthma, the dyspnea having increased of late to an alarming extent. The history was entirely negative; syphilis could not be traced. The patient appeared to be in great distress. His respiration was labored, noisy and accelerated; on exertion his face had a livid color and was covered with a cold, clammy perspiration. The stenosis of the larynx was extreme. The ventricular bands were greatly thickened and the vocal cords buried in masses of infiltrated tissues. The encroachment on the lumen of the larynx increased in the subglottic space, the opening for breathing being scarcely the size of a thin lead pencil.

The smallest tube of the intubation set for adults was introduced without any difficulty. It was well oiled and the larynx had been previously anesthetized with a 5 per cent. solution of cocain. The tube is somewhat larger than the largest tube of the set used for children. The patient could readily breathe through the tube and complained of no pain. It was my intention to permit the tube to remain in the larynx for twenty-four hours, but on the following morning, about fifteen hours after the introduction, the patient returned and begged me to remove the tube. He stated he was greatly annoyed by it and could not take any food whatever. I extracted the tube without any difficulty, with the understanding that it was to be reintroduced in the evening. The patient was greatly relieved, was able to take some water, and left my office after a few minutes feeling comparatively comfortable. About fifteen minutes later he was found dead on the sidewalk, about a half square from my office. He had walked about one and a half squares when he felt bad and asked the driver of a passing wagon to take him to my office. Scarcely had he been seated when he fell back and died before he could be lifted from the wagon. A physician who happened to pass there shortly afterward found no sign of life.

The unfortunate accident can be easily explained. After the pressure exercised for fifteen hours by the tightly fitting tube upon the infiltrated tissues had been suddenly relieved a subglottic edema ensued causing a fatal issue within a short time. This rather unusual case teaches us a lesson to keep a patient upon whom intubation for a chronic stenosis has been practiced, under strict surveillance for some time after the extraction of the tube.

Case 5. Severe spasmodic cough and neuralgia after a nasal operation. Miss B. K., aet. 24, consulted me on account of excessive sneezing which had been troublesome for several years, but had become well-nigh exhausting of late. The anterior and lower portion of the left middle turbinated was enlarged to almost the size of a cherry, of a deep purple hue, and touching the septum. Upon the lightest touch with the probe an excessive fit of sneezing was sure to follow, which would immediately stop after the application of a 4 per cent. solution of cocain. This hypertrophy was removed with the cold snare. One half hour after the operation the patient had a most severe attack of coughing, a symptom which was 
entirely new, and not long thereafter a most intense neuralgia of the left side of the face developed; nothing short of morphin and chloral hydrate would give her rest during the following night. The neuralgia lasted for several days when it gradually disappeared, while the spasmodic cough vanished only after two and one-half weeks. There was no local condition present that could account for it, the wound having nicely healed without any disturbance and without further interference. There was af terward no return of these symptoms, nor of the sneezing.

These few cases are reported simply for the reason that they appeared to me somewhat unusual. In fact all of them at the time, when my experience was less, were rather alarming, although fortunately, with the exception of the fourth case, they ended well. Yet, as any one is likely to meet at any time with accidents which are not common, and which can not be expected according to our usual experience, I thought these cases, collected at random from my note book, of sufficient interest to be placed on record.

\section{DISCUSSION.}

Dr. J. E. Logan, Kansas City, Mo.-I have had some experience similar to Dr. Thorner's. My patient was similarly affected with this extreme irritability of the nostrils and experienced a great deal of the same trouble of excessive sneezing. I only refer to the case to make this suggestion, that in most of these cases the focus of irritation is in the anterior chamber. I have found that the application of the galvanic cautery to the middle turbinate has brought me better results than complete or partial removal with the snare. In this patient I removed considerable portion of the middle turbinate and packed with iodoform gauze, and for several months afterward the patient had a disturbed sense of smell. He was troubled with the odor of iodoform for months. It disturbed me, and while in New York I had him go to a friend of mine and he confirmed my opinion that it was due to the very nervous temperament of the patient. The sneezing did not return, but the perverted sense of smell remained for six or seven months.

Accidents liable to happen as the result of operations in the nasal cavity are many, for the reason that the nose and throat, especially the laryngeal cavity, are the seats of great reflex action, more so probably than any other cavity of the body and I am not surprised that the removal of the enlarged follicle was the cause of the aphonia. I have found the cause of this sudden aphonia to be very hard to explain. In the case in which there was involvement of the cords without loss of muscular power it would lead me to suspect hysteria; the cords would be under the control of the patient to a certain extent. I have had this experience with hysteric patients.

Dr. W: E. Casselberry, Chicago, Ill. - I wish to say in support of Dr. Thorner, that I believe one may have temporary impairment of the voice reflexly produced by operations on neighboring parts independently of a suspicion of hysteria. In one case of combined operation for tonsils and adenoids on a boy 5 years of age, the tonsils being removed with the cold wire snare, after the operation he spoke in a high unnatural voice, which lasted for about six days, when he gradually regained his proper tone. It could not be ascribed to other than irritation of peripheral nerves.

In reference to the case involving the middle turbinated body, I would ascribe the loss of memory to the use of cocain. I have seen some curious temporary mental effects produced by it. In regard to the middle turbinated body, I would say that while I have advised operations upon it under certain conditions, I think we should be cautious. From the intimate association of the vessels of the middle turbinated body with the cerebral meninges, it is perhaps surprising that serious results should not be more frequently encountered. Operations upon this body should be restricted to those cases in which there is a very clear and decided indication therefore.

Dr. Cline-In Dr. Thorner's case in reference to the aphonia
I am inclined to think that it was the result of the cocain. I recall three similar cases which I think were due to it. One, a man of very nervous temperament whose sphincter muscles were paralyzed for several hours. He also seemed to be unable to speak, which I attributed to the cocain. I am not in favor of the free use of cocain unless I know my patient.

Dr. Thorner-The discussion has been partly diverted to. cocain poisoning which I did not consider. The operation which caused the temporary loss of memory was done on the soft parts of the middle turbinated and not on the bone itself. Operations on the middle turbinated are much more dangerous than on the other parts. If you will examine the connections closely you will readily see that it is a dangerous place to operate and the wonder is that we do not have accidents more frequently. As to the operation for the removal, I always prefer the cold snare. This simply cuts away the bone as clean as can be done. The old way of tearing out is certainly dangerous. The galvano-cautery is also very dangerous here. I have heard of a number of deaths that were the result of cauterization. And how many are not reported? There are others who favor the removal with the cutting forceps, which if properly done is also well adapted for operations of this kind.

The principal danger of operations in this vicinity lies in the anatomic relations. We have the immediate region of the orbit separated from the ethmoid cells by the lamina papyracea. We have also the nerves and blood vessels passing through the foramen opticum, through the fissura sphenoidalis, etc. The roof of the nasal cavity is thin and separates it from the brain. And yet there are and will be cases which must be operated upon.

Dr. John O. Roe, Rochester, N. Y.-In regard to the case in which the effect of the cocain seemed to be quite unusual, I am also of the opinion that all the manifestations were the result of cocain. Some patients are so extremely susceptible to its influence that all sorts of neurotic manifestations are caused by it. Notwithstanding this fact I daily use cocain in my work freely and indiscriminately without the slightest bad results. With patients who are so extremely susceptible to cocain we must use it with great care. In the case of a patient under my care not long ago, one single drop of a 4 per cent. solution put into her nose would cause agitation of the heart, and a few drops would cause extreme dyspnea, so much so that suffocation would seem imminent. I was obliged to resort to general anesthesia in order to perform the necessary operation in her nose. I find that by giving these patients quite a large dose of tincture digitalis a short time before employing the cocain and giving whisky in sufficient doses to very nearly intoxicate, this susceptibility to cocain is overcome, so that all these unpleasant symptoms and cocain complications are entirely obviated. In the case of the patient just referred to, I have had occasion recently to do a slight operation on her nose, and by the use of digitalis and whisky I was enabled to use all the cocain necessary to complete the operation without pain. In regard to the cerebral complications resulting from operations in the nose, $\Upsilon$ have observed in the cases reported, that these complications more frequently result from operations upon the middle or superior turbinated bone than in any other portion of the nose. These bodies are a portion of the ethmoid bone, which is closely connected with the cranial cavity, and it is for this reason that under certain conditions disturbances in these parts may be transmitted to the meninges.

Dr. Robert C. Myles, New York, N. Y.-As for the fainting from the use of cocain $I$ think it is very common. I have adopted the plan of preventing the solution from extending over a larger area than that on which I intend to operate, and I believe a strong solution is better than a weak one. I also employ the reclining position as a remedy. I have noticed in a number of cases that were in the incipient stage of fainting, when they were placed in the horizontal position they recov- 
ered at once. Sometimes a hot room will cause fainting. A peculiarity is that there is very little absorption about the tongue and throat, but in the nose it is very rapid. In regard to operating on the middle turbinated I think that the old way of tearing the body away with forceps is unsurgical and unsafe. The membrane continues through the cribriform plate into the cranium, and it is remarkable that serious consequences are not reported more frequently. The turbinated body can be removed neatly and effectively with the ethmoid clippers or scissors and a cold wire snare.

\section{A CLINICAL STUDY OF TWENTY-ONE THOU- SAND CASES OF DISEASES OF THE EAR, NOSE AND THROAT.}

\section{BY SETH SCOTT BISHOP, B.S., M.D., LL.D.}

Surgeon to the Illinois Charitable Eye and Ear Infirmary; Professor of tology in the Post Gractuate Medical School and Hospital; Nose. Throat and Ear in the Illinois Medical college, etc. cHICAGo.

The following statistic table of 15,300 cases, combined with a table of $\tilde{0}, 700$ cases already published, represent the records of 21,000 treated during the past seventen years at the Illinois Charitable Eye and Ear Infirmary in Chicago. The following table was compiled for me by my assistant, Dr. Charles L. Enslee.

My first classification was instituted for the purpose of establishing a basis of calculation of the influence, if any, exerted by occupation, age or sex in the causation of diseases of the ear, nose and throat.

The condition of each patient at the time he first presented himself at the clinic is presented to determine the relative frequency of the different diseases.

As is common in charity hospitals, a considerable number of those who applied for treatment belonged to that class of laboring people who have no definite trade or fixed occupation. In order to facilitate investigation and simplify the tables as far as possible, all those occupations that were closely related to each other in nature and effects were grouped under one heading. For example, under the classification of clerks were embraced salesmen, bookkeepers, office employes, etc.; with teamsters were grouped car drivers, peddlers, etc.: cooks and bakers were classified together; brass molders, iron molders, etc., were classified with iron workers; plumbers, gas and steam fitters appear together; such closely allied occupations as stone cutters, stone masons, bricklayers and plasterers in which the influences and exposures are very similar, are grouped together under the head of day laborers, a term borrowed from the laborers themselves.

The combined tables show that of the 21,000 cases there are 11,119 patients with occupations, classified under twenty-eight headings. Of this number, 3,813 had out-door work and 7,306 in-door. About 34 per cent. are out-door occupations and 66 in-door; or about twice as many in-door occupations as out-door.

The largest number of any one class were in-door workers, 3,045 domestic servants. Next in order were about half that number of the out-door class, or 1,508 day laborers. Then follow groups of the next highest numbers; 858 clerks, 460 iron workers, 452 carpenters, 400 sewing women, 378 factory workers of all kinds, all in-door occupations before we reach the out-door class again in going down the scale.

While the great stores and factories furnish a large number of patients, the homes contribute 5,615 females, including the servants, seamstresses and women without occupation, or more than one-fourth the whole number of the combined tables. These facts are significant when we take into account the slight difference between the number of males and females affected under the age of 15 years. Out of 6,162 children under 15 years of age there were 1,484 boys and 1,590 girls between the ages of 6 and 15 years; and 1,641 boys and 1,447 girls under 6 years.

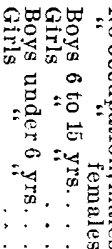

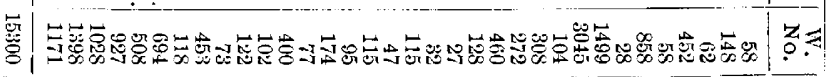

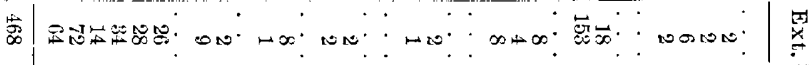

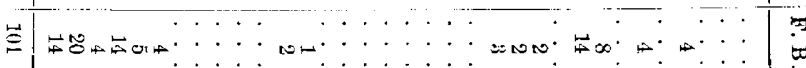

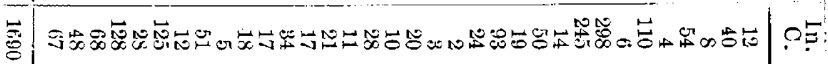
岳

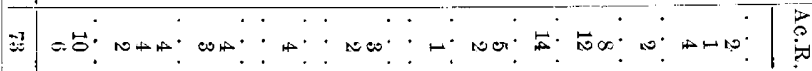

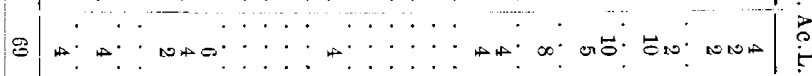

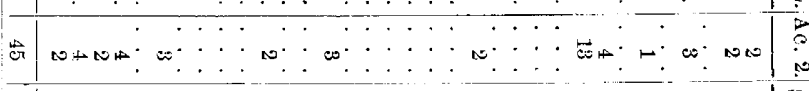

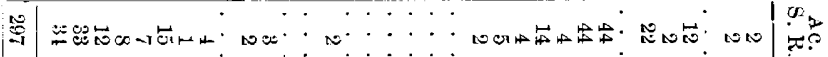

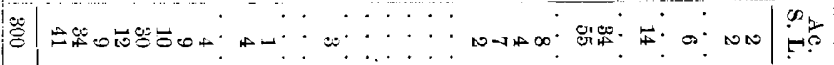

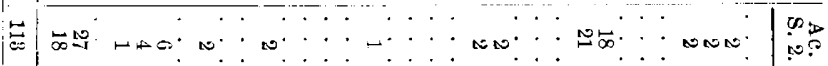

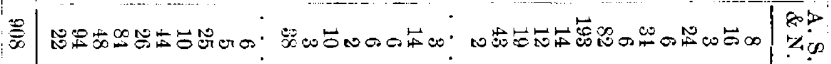

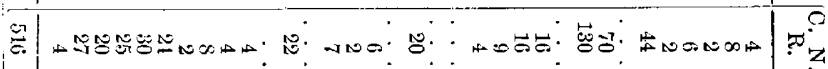

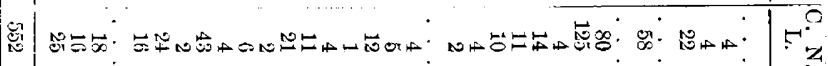

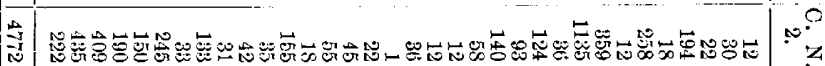

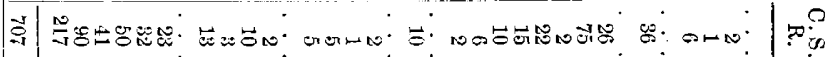

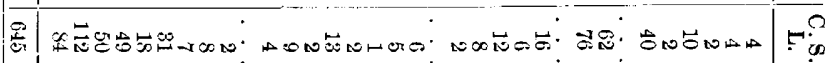

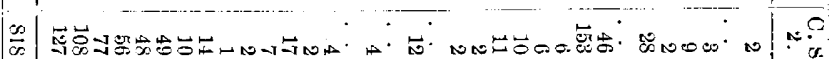

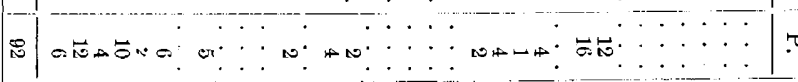

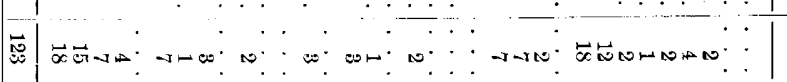

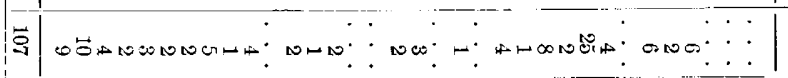

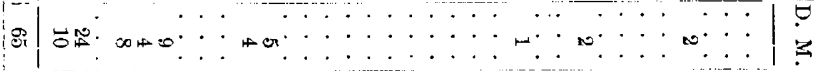

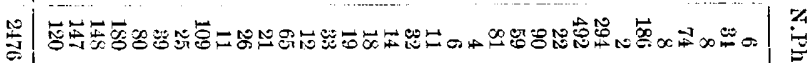

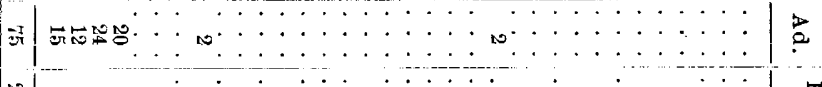
急 1 From the writer's forthcoming book on Diseases of the Ear, Nose and Throat (in press).

THE ABIBREVIATIONS EMPLOYED ARE:

W. No.-whole number.

Ext.- diseases of the external ear. 